\title{
Red Ear Syndrome: Uma síndrome rara associada à cefaleia primária
}

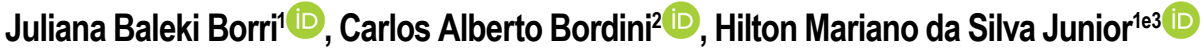

'Pontifícia Universidade Católica de Campinas, Campinas, São Paulo, Brasil

${ }^{2}$ Centro Universitário Municipal de Franca, Franca, São Paulo, Brasil.

${ }^{3}$ Hospital Municipal de Campinas Doutor Mário Gatti, Campinas São Paulo Brasil

\section{Introdução}

A Red Ear Syndrome (RES) é uma afecção rara (cerca de 50 casos idiopáticos foram publicados em 24 anos), de etiologia e tratamentos ainda mal definidos. Caracteriza-se por hiperemia da orelha descrita como uma sensação de queimação, e na maioria dos casos idiopáticos está associada a cefaleia primária, mas pode ocorrer isoladamente. O objetivo deste trabalho é relatar um caso de RES relacionado a enxaqueca. A falta de conhecimento sobre esta entidade retarda o diagnóstico e prejudica a qualidade de vida do indivíduo, visto que em alguns casos a dor pode ser incapacitante.

\section{Objetivos}

Reportar um relato de caso sobre a RES em conjunto com enxaqueca.

\section{Material e Métodos}

Relato de uma mulher, 31 anos, apresentou-se há 10 anos com dor aguda, edema e eritema acentuado no pavilhão da orelha, ocasionalmente acompanhada por hiperidrose e queimação local. Estes, ocorreram de forma espontânea ou foram induzidos por gatilhos. Durante os ataques, o resfriamento era o único meio de alívio. A paciente relatava associação clara entre a orelha vermelha e algumas crises de enxaqueca. Extensa investigação laboratorial e radiológica não mostrou anormalidades.

\section{Resultados}

O diagnóstico dessa paciente é de RES. Existem duas formas da afecção: idiopática que ocorre mais frequentemente em pessoas jovens, sendo espontânea ou associada a cefaleia; e a forma secundária associada a disfunção da porção superior da coluna cervical ou a disfunção temporomandibular. A possível explicação da síndrome da orelha vermelha se baseia em aspectos anatômicos, e acredita-se que a ativação do sistema trigêmino-vascular seja a via comum para ambas as formas. Essa ativação resultaria nos reflexo trigêmino-autonômico e trigemino-cervical, responsável por sintomas autonômicos e pela RES, respectivamente.

\section{Conclusões}

O fenômeno da orelha vermelha é caracterizado por ataques de dor em queimação e rubor na orelha de forma repentina ou induzida por gatilhos. Os ataques podem durar minutos a horas em conjunto com cefaleias primárias. A incerteza sobre a etiologia desta síndrome é um obstáculo para o tratamento. Novos relatos sobre o distúrbio são importantes para aumentar o conhecimento dos médicos e profissionais da saúde e diminuir o retardo diagnóstico e sofrimento dos pacientes. Além disso, esse relato oferece novos dados que poderão ser estudados e comparados para esclarecer a fisiopatologia e elaborar um tratamento eficaz.

Palavras-chave: Síndrome rara, Cefaleia, Dor orofacial 